\title{
Transdisciplinary Collaboration and Lifelong Learning: Fostering and Supporting New Learning Opportunities
}

\author{
Gitta Domik ${ }^{1}$ and Gerhard Fischer ${ }^{2}$ \\ ${ }^{1}$ University of Paderborn, Warburgerstrasse 100, D-33098 Paderborn, Germany \\ ${ }^{2}$ University of Colorado at Boulder, Boulder, CO. 80301-0430, USA \\ domik@uni-paderborn.de \\ gerhard@colorado.edu
}

\begin{abstract}
The contexts provided by the world of the $21^{\text {st }}$ century require that our societies rethink and reinvent learning, teaching, working, and collaboration. A first basic challenge insufficiently addressed by prior research and practice is that almost all of the significant problems of tomorrow will be systemic problems, which cannot be addressed by any one specialty. These problems require transdisciplinary collaboration that focuses on opportunities for knowledge workers to work in teams, communities, and organizations that encompass multiple ways of knowing and collaborating. A second basic challenge is that learning can no longer be dichotomized into a place and time to acquire knowledge (school) and a place and time to apply knowledge (the workplace). To educate students today requires that we provide them with opportunities and soft skills to become lifelong learners.

This paper (1) discusses the conceptual frameworks that we have developed to address these challenges; (2) describes our implementation and experience teaching a one semester graduate course based on our framework; and (3) discusses implications and future opportunities.
\end{abstract}

Key words: $21^{\text {st }}$ century competencies, systemic problems, transdisciplinary collaboration, lifelong learning, self-directed learning, learning on demand, computer science education, breadth-first teaching, Long Tail learning, reflective communities

\section{Introduction}

Many real-world problems have become too complex to solve for a single expert out of one discipline. The knowledge relevant to solve complex problems is increasingly distributed among many people requiring socio-technical environments [1] that bring together people with different, complementary, and often-controversial points of view to form a community. Despite these widely accepted attributes, contemporary higher education is primarily characterized by receiving knowledge out of one single department (usually synonymous with one single discipline), therefore forming specialists with depth in unidisciplinary 
knowledge and discipline-dependent characteristics ("stereotype"). We support "tribal behaviour" in our departments, creating "artists", "computer scientists" and "urban planners", each group harmonizing their own world and suffering from Groupthink [2].

Another major challenge facing our educational system is that the body of knowledge to be taught in a Computer Science (CS) curriculum expands continuously as testified by the changes in the Computing Curricula recommendations by ACM and IEEE ([3], [4]). Even after our students graduate, the body of knowledge will expand and they will be responsible to acquire knowledge without extrinsic motivation (e.g. mandated assessments) both within their own discipline, but in collaboration with others coming not only from their own discipline.

To respond to these challenges, we are engaged in research activities and educational innovations focused on fostering and supporting new learning opportunities based on inter- and transdisciplinary collaboration and lifelong learning that are aimed at (1) having students practice meaningful collaboration with other disciplines, and (2) transforming students from being educational consumers to become socially competent, responsible, self-directed learners.

This paper first defines and explores transdisciplinary collaboration and lifelong learning. We postulate two strategies in a framework, namely breadth-first and Long Tail, that aid in the learning process, before we describe our implementation and experience teaching a one semester graduate course based on our framework. Finally, we discuss implications and future opportunities.

\section{Transdisciplinary Collaboration}

Transdisciplinary collaboration is a group process between individuals educated and knowledgeable in different disciplines (such as: computer scientists, biologists, designers of new media, urban planners, etc.). In exploring these collaborations, researchers and educators use the terms multidisciplinarity, interdisciplinarity, and transdisciplinarity, often without clearly distinguishing among them, though these terms are well defined and distinguished by e.g. Klein [5], Rosenfield [6] and Nicolescu [7]. In short,

- multidisciplinarity means that several disciplines are being involved either in a sequential or juxtaposed mode;

- interdisciplinarity implies integration or blending of knowledge from different disciplines;

- transdisciplinarity places the highest demand with the objective to form new knowledge from available unidisciplinary awareness.

Transdisciplinarity in education requiring the creation of new organizational framework for knowledge out of separate disciplines demands collaboration of researchers and faculty from different disciplines. Therefore, in most standard university courses, interdisciplinary collaboration (feasible with a single educator) will be used to prepare for later transdisciplinary or interdisciplinary collaboration among various disciplines. 
Providing students with opportunities in inter- and transdisciplinary education as a preparation for engaging later in transdisciplinary collaboration raises the issues at what educational level will students be mature enough to blend knowledge or to form new knowledge? Derry and Fischer [8] specifically argue for a transdisciplinary education at the graduate level. Rosenfield [6] also places transdisciplinary training at the early graduate level, because a solid grounding in their own discipline, respect for the contributions that other disciplines can make, and the sensitivity to cooperative endeavour is a prerequisite to perform transdisciplinary research.

Stokols [9] observes in his scientific collaborations the following factors supporting productive and rewarding collaboration between disciplines:

- members ${ }^{6}$ strong commitment to achieving transdisciplinary goals and outcomes;

- interpersonal skills of team leaders;

- history of prior collaboration among team members;

- spatial proximity of team members' offices and laboratories;

- schedule frequent face-to-face meetings for brain-storming of ideas;

- establish electronic linkages among participants;

- foster institutional supports for these objectives.

In addition, he articulates the following factors constraining transdisciplinary collaboration:

- substantial time required to establish common conceptual ground and informal social ties;

- unrealistic expectations and ambiguity about shared goals and products;

- conflicts among alternative disciplinary views of science; and

- bureaucratic impediments to cross-departmental collaboration.

Stokols research is grounded in an analysis of scientific collaborations (to improve understanding of nicotine addiction), our research activities transferred these indicators into educational settings. Table 1 transfers educationally relevant indicators to a constructive condition in education.

From Table 1 we can derive two issues that are paramount: (1) students need to find a common ground for their communication as early in the course as possible [10]; (2) students need projects that they feel committed to out of personal interest. Once these concerns are solved, the other issues (e.g. team building process, enforcing meaningful group meetings and electronic linkage) will be easier to solve.

\section{Lifelong Learning}

In the $21^{\text {st }}$ century, learning can no longer be dichotomized into a place and time to acquire knowledge (school) and a place and time to apply knowledge (the workplace). Todays citizens are flooded with more information than they 


\begin{tabular}{|l|l|}
\hline Demand by Stokols [9] & How educators can be of support: \\
\hline $\begin{array}{l}\text { support members' strong commitment to } \\
\text { achieving transdisciplinary goals and out- }\end{array}$ & $\begin{array}{l}\text { support students in } \\
- \text { finding unique topics they feel pas- } \\
\text { sionate about; } \\
- \text { team building process }\end{array}$ \\
\hline $\begin{array}{l}\text { establish common conceptual ground and } \\
\text { informal social ties }\end{array}$ & $\begin{array}{l}\text { establish common language and help es- } \\
\text { tablish social ties }\end{array}$ \\
\hline $\begin{array}{l}\text { schedule frequent face-to-face meetings } \\
\text { for brain-storming of ideas }\end{array}$ & $\begin{array}{l}\text { encourage and enforce face-to-face meet- } \\
\text { ings; give help with structure of these } \\
\text { meetings }\end{array}$ \\
\hline $\begin{array}{l}\text { establish electronic linkages among par- } \\
\text { ticipants }\end{array}$ & $\begin{array}{l}\text { encourage the use of free electronic link- } \\
\text { ages, e.g, Wikis, Skype, or ICQ addition- } \\
\text { ally to Email }\end{array}$ \\
\hline $\begin{array}{l}\text { constrain unrealistic expectations and } \\
\text { ambiguity about shared goals and prod- } \\
\text { ucts; constrain conflicts among alterna- } \\
\text { tive disciplinary views of science }\end{array}$ & $\begin{array}{l}\text { participate in selected face-to-face meet- } \\
\text { ings to constrain "tribal behaviour" } \\
\text { through own interpersonal and interdis- } \\
\text { ciplinary skills }\end{array}$ \\
\hline
\end{tabular}

Table 1. Demands for Transdisciplinary Collaboration in Science Transferred to Education

can handle, and tomorrows workers will need to know far more than they can learn today in school.

Lifelong learning is an essential challenge for inventing the future of our societies; it is a necessity rather than a possibility or a luxury to be considered. It complements and transforms industrial-age with knowledge-age approaches (see Table 2). Lifelong learning is more than adult education and/or training [11]: it is a mindset and a habit for people to acquire. Lifelong learning creates the challenge to understand, explore, and support new essential dimensions of learning such as: (1) self-directed learning, (2) learning on demand, (3) collaborative learning, and (4) organizational learning. These approaches need new media and innovative technologies to be adequately supported.

A significant weakness of current educational systems is that they do not deliberately educate for lifelong learning. Rather, current systems require that at a certain point in their development, learners in all walks of life leave school in which they were mostly consumers of educational material and throw a "big switch" to become socially competent, responsible, self-directed learners who successfully use tools and technologies to enrich their personal and working lives and who collaborate with one another to solve local and global problems. Yet little of their previous educational experiences have prepared them to do any of this. 


\begin{tabular}{|c|c|c|}
\hline Industrial-Age Approaches & & Knowledge-Age Approaches \\
\hline $\begin{array}{l}\text { there is a "scientific", best way to learn } \\
\text { and to work (programmed instruction, } \\
\text { computer-assisted instruction, produc- } \\
\text { tion lines, waterfall models) }\end{array}$ & $\Rightarrow$ & $\begin{array}{l}\text { real problems are ill-defined and wicked; } \\
\text { design is argumentative, characterized } \\
\text { by a symmetry of ignorance among } \\
\text { stakeholders }\end{array}$ \\
\hline $\begin{array}{l}\text { separation of thinking, doing, and learn- } \\
\text { ing }\end{array}$ & $\Rightarrow$ & $\begin{array}{l}\text { integration of thinking, doing, and } \\
\text { learning }\end{array}$ \\
\hline $\begin{array}{l}\text { task domains can be completely under- } \\
\text { stood }\end{array}$ & $\Rightarrow$ & $\begin{array}{l}\text { understanding is partial; coverage is im- } \\
\text { possible }\end{array}$ \\
\hline $\begin{array}{l}\text { objective ways to decompose problems } \\
\text { into standardizable actions }\end{array}$ & $\Rightarrow$ & $\begin{array}{l}\text { subjective, situated personal interests; } \\
\text { need for iterative explorations }\end{array}$ \\
\hline $\begin{array}{l}\text { all relevant knowledge can be explicitly } \\
\text { articulated }\end{array}$ & $\Rightarrow$ & $\begin{array}{l}\text { much knowledge is tacit and relies on } \\
\text { tacit skills }\end{array}$ \\
\hline teacher / manager as oracle & $\Rightarrow$ & teacher / manager as facilitator or coach \\
\hline $\begin{array}{l}\text { operational environment: mass markets, } \\
\text { simple products and processes, slow } \\
\text { change, certainty }\end{array}$ & $\Rightarrow$ & $\begin{array}{l}\text { customer orientation, complex products } \\
\text { and processes, rapid and substantial } \\
\text { change, uncertainty and conflicts }\end{array}$ \\
\hline
\end{tabular}

Table 2. Contrasting Industrial-Age and Knowledge-Age Approaches

To enrich the cultures of work and learning and the personal lives of learners by cultivating mindsets and skills for lifelong learning, students must be prepared, not only to excel in traditional academic settings, but to contribute knowledge and effort to a world characterized by change, uncertainty and pressing transdisciplinary problems that will require new forms of scholarship, publication, communication and participation.

Against this background, we have articulated the following credo for transdisciplinary collaboration and lifelong learning that grounds the research and education activities discussed in this paper:

"If the world of working and living relies on collaboration, creativity, definition and framing of complex problems and if it requires dealing with uncertainty, change, and intelligence that is distributed across cultures, disciplines, and tools - then education should foster transdisciplinary competencies and mindsets that prepare students for having meaningful and productive lives in such a world."

\section{Innovative Teaching and Learning Strategies: Breadth-First and Long Tail}

\subsection{Teaching Different Disciplines out of the CS Department}

Computer science students are expected to be firmly grounded in their own discipline and possess depth in the body of knowledge as described by the Computing Curricula 2001[3]. Soft skills, as necessary as they are for the success of our graduates in the later work place, are not defined in [3] as a core or optional 
topic. Nevertheless, computer science students must and will learn essential soft skills during their years at the university: e.g. communication skills (in speech, in writing, visual), or working in teams. "[Soft] skills should not be seen as separate but should instead be fully incorporated into the computer science curriculum and its requirements" as requested in [3]: Educators teach communication skills while giving a seminar or advising a bachelor or master thesis; or use software projects to teach team work in software engineering.

We have to aim at teaching transdiciplinary collaboration and lifelong learning in a similar mode: focusing on the content of our CS curriculum but at the same time preparing students for that important competency. While a seminar is better than a lecture course in teaching the competency of oral presentation, we can identify in [3] areas of knowledge that will hold that promise for transdisciplinary collaboration, e.g. the area of Graphics and Visual Computing, where courses on visualization, augmented reality, animation, or (more recently) game development, deepen the knowledge of graphics architecture or rendering algorithms, but at the same time gain from the presence of students of other disciplines (e.g. media sciences, architecture, physics).

Technical competency is ranked high in the job market, so students of other disciplines are showing sufficient interest in joining computer science courses if the prerequisites are manageable [12]. While an electrical engineering student might be interested in OpenGL programming to better utilize her knowledge on signal processing, a media design student might have interest in Flash scripting or a student of journalism to set up a Wiki.

Acquiring skills in a successful course of mixed disciplines (at the graduate level, as recommended earlier in this paper) will need an appropriate balancing of breadth and depth of participating students. In a suitable project for a visualization course for computer science and physics students using air flow data, computer science students will gain depth in developing and implementing real-time flow visualization algorithms, while physics student will only acquire breadth knowledge in that area. (With a joint lecturer of the physics department involved, computer science students can acquire breadth knowledge of modelling air flows while physics students can deepen their previously theoretical knowledge in fluid dynamics.) There should be no need to take Physics 101 for CS students, or for Physics students to take the CS introductory course to $\mathrm{C}++$, to work jointly on projects.

Sometimes CS educators complain about how long it takes to teach nontechnical students the skills of programming before "real" work on joint projects can start, when they should concentrate on developing a common ground [10] for all students so they could work together on a solution, each grounded in the skills of their own discipline and extending into the other discipline only to build necessary overlaps. 


\subsection{Breadth-First: Finding a Common Language between Disciplines}

Stokols [9] demands to establish a common conceptual ground and informal social ties early on in the project, so that the time left to work together is maximized. Finding a common conceptual ground means bridging spatial, temporal, technological, and disciplinary distances [13]. The major issue in a course will be to first empower students of diverse disciplines to communicate with each other. We propose to use a breadth-first strategy, where we start with a holistic view of each topic to teach (breadth) and undermine it with an application; then use depth to the level the students are ready for. The first part (breadth) provides overall understanding of the topic on an entry level. The application should give extra motivation to learn more about this topic. The second part (depth) will built up through sophisticated layers and is designed for a specific discipline. If a topic is prepared breadth-first, then the breadth part of the course can be simultaneously taught to students of various disciplines. Advantages for a breadth-first approach are [14]:

- CS students get a holistic view of a topic before they learn about more complicated details;

- CS students can then move on to any depth-level;

- students of other disciplines learn of the importance of a topic through the goal of the application;

- students of different backgrounds can be taught together at the breadthlevel;

- all students are being taught the same "language" to describe problems on and solutions to the topic;

- application oriented approaches are motivational to both men and women.

The result of this approach is that breadth-first leaves students of different disciplines with a common language that they can use to discuss goals and strategies for joint projects.

Let us assume that students of diverse disciplines work together in groups on a visualization project. Language differences will become obvious when students discuss the quality of a visual representation and call it "an effective picture". In the mind of an art major this might mean "aesthetic" picture, a computer scientist will think of a (cost) efficient representation. Introducing the terms "expressive" and "effective" [15] to clearly define quality criteria for visual presentations during the first lectures will later be helpful when students discuss their project goals. "Expressive" and "effective" will then replace their discipline-dependent quality descriptors.

This common language is essentially the most important ingredient for transdisciplinary collaboration, because without it the door stays open for misunderstandings, unrealistic expectations and ambiguity about shared goals. It also opens the opportunity to provide additional depth to CS students either by (1) using learning tools providing breadth in the upper levels, and depth in the lower levels; (2) individually helping CS students find references for depth-topics; or (3) offering a seminar (only for CS students) parallel to an interdisciplinary course. 


\subsection{Long Tail: Passion-Based and Self-Motivated Learning}

One of the major roles for new media and new technology from a transdisciplinary collaboration and lifelong learning perspective is not to deliver predigested information to individuals, but to provide the opportunity and resources for engaging them in authentic activities, for participating in social debates and discussions, for creating shared understanding among diverse stakeholders, and for framing and solving personally meaningful problems. Our research is grounded in the fundamental belief that all humans (1) have interest and knowledge in one or more niche domains and (2) are eager to actively contribute in personally meaningful activities [16]. The richness of these interests and the passion of the humans involved in them leads to the Long Tail [17] of distributed knowledge [18]. The fundamental transformation of a Long Tail perspective refers to at least two aspects: (1) learning and discovery about exotic, but important topics outside the mainstream education curriculum, and (2) the opportunity to communicate with people who share similar niche interests anywhere in the world on a regular basis.

The Long Tail theory explores how our economy and culture is shifting from mass markets to million of niches. It analyzes the effect of technologies that have made it easier for consumers to find and buy niche products based on the "infinite shelf-space effect" supported by new distribution mechanisms that eliminate the bottlenecks of broadcast and traditional bricks-and-mortar retail.

The concept of the Long Tail (as developed in business environments) [17] postulates that our culture and economy are increasingly shifting away from a focus on a relatively small number of products and markets at the head of the popularity curve toward a huge number of niches in the tail. The research in our Center for Life Learning \& Design (L3D) reinterprets and explores the Long Tail business environments for transforming learning and education $[18,19]$ as seen in Table 3.

\begin{tabular}{|l|l|}
\hline Web-Based Businesses & Learning and Education \\
\hline unlimited shelf-space & unlimited knowledge \\
\hline megahits (head) & core curriculum (head) \\
\hline niche markets (tail) & passion for unique topics (tail) \\
\hline hybrid model of distribution & hybrid model of learning and discovery \\
\hline $\begin{array}{l}\text { many interesting books, movies, songs } \\
\text { will not enter the traditional marketplace }\end{array}$ & $\begin{array}{l}\text { many interesting topics and ideas will not } \\
\text { be taught in traditional learning environ- } \\
\text { ments }\end{array}$ \\
\hline
\end{tabular}

Table 3. Long Tail Concepts in Business and in Learning and Education 
Assessing passion-based, self-motivated learning based on the Long Tail perspective requires fundamentally different assessment approaches compared to what standard educational testing can offer [20]. L3D is currently researching to understand the benefits to the kinds of education that this approach can afford, such as the ability of learners to pursue those topics of interest to them and to take responsibility for their own education (examples of courses can be found at http://13d.cs.colorado.edu/ gerhard/courses/). By focusing on the tail of the Long Tail, we will not ignore the head but we will create a synergy between the two. Interest driven activities are boundary crossing: they move across settings of home, school, work, community, and online. In the context to enhance the competency of transdisciplinary collaboration and education this means that the Long Tail approach will be grounded in the following assumptions [21]:

- The activities of the head are the course topics that computer science students will improve their depth in, and students of other disciplines will learn to understand on a breadth level. The motivation for participation is mostly determined by extrinsic motivation (e.g. for credits; to improve job market value).

- The activities of the tail (the major contribution of Long Tail learning) should be focused on interest and passion allowing learners of all disciplines to pursue personally meaningful problems. The motivation for participation is mostly determined by intrinsic motivation. Learning and discovery are facilitated by passion-based participation on niche topics.

In the following chapter the here presented strategies have been applied at the University of Paderborn to a one semester graduate computer science course with 48 participating students representing three different groups of disciplines: computer science, business information systems and non-technical students (e.g. from media science or the German language department).

\section{Implementation and Assessment of our Framework in a Graduate Course}

Setting of the course. The University of Paderborn has 14.000 students and is divided into five faculties. The course "Data and Information Visualization" is offered in the CS graduate program as part of a computer graphics module. For the Summer Term 2009 it was opened to graduate students of all disciplines and thus gained 48 participants from three different faculties: 29 CS students (Faculty of Computer Science, Mathematics and Electrical Engineering), 14 business information systems students (Faculty of Business Administration and Economics), 5 non-technical students (media science students and literature students - all from the Faculty of Arts and Humanities). CS students have to be at graduate level, and completed at least a basic computer graphics course and one advanced rendering course. The visualization course included 90 minutes of lecture and 45 minutes of lab time per week over a period of 15 weeks. Students 
received 4 ECTS (European Credit Transfer and Accumulation System) for the course, which translates to an expected effort of 100-120 hours of work on the students side. In the lectures students learn methods and techniques to visualize information and data in an expressive and effective way. Lab time is being used to practice concepts and techniques. Starting in week 4, students worked on interdisciplinary projects of their choice in teams of their choice (with the restriction that each team had to hold a sufficient disciplinary mix).

Breadth-First: finding a Common Ground. Computer-generated visualization (including visualization of data derived from scientific measurements or scientific computing, or collected by humans or machines) holds multitudes of examples useful for teaching. Most of these are multidisciplinary, owing the context to an application outside CS, while the interactive graphics is clearly of interest to our CS students. Additionally, perception, design, and other areas of disciplines outside CS, play an important role in computer-generated visualization. The core topics to teach computer-generated visualization are: definitions; data; user and tasks; mapping from data parameters to visual attributes; representation techniques; interaction issues; concepts of the visualization process; and systems and tools. These eight core topics constitute the head of the knowledge to be conveyed in a visualization course [22]. Using a "Breadth-First" learning tool (the top levels constitute the breadth that is comprehensible for students of any discipline, [14]) these core topics were taught during lectures. Of the typically four levels for each core topic (increasing level meaning increasing depth) level one and two were presented in class, suitable for all disciplines. This strategy helps both to teach the content of visualization to all students, but also to remove misunderstandings in the communication by providing a common language.

Long-Tail: finding topics of personal interest. Starting in the first lecture, each core topic and concept was enforced by visualization examples in an application context. This aided both the breath-first approach in teaching as well as the later search for unique project topics for students. Examples given included: visualization of large, multivariate environmental data; software visualization (e.g. algorithm animation, visualization of large code parts), augmented reality to support surgery; visualization of large information spaces, such as demographic data, etc. In each of these cases visualizations aid in the interpretation of complex data for a specific context (often outside CS), but are only possible through special visualization techniques: e.g. animation, flow visualization, GPU-based volume rendering, etc. These visualizations constituted the tail of visualization knowledge.

In week 3 (out of 15 course weeks), students had each to submit a complex data set they desired to visualize as their semester project. They were asked to describe the data in a conceptual form (something they learned to do in the previous lecture), set visualization goals, suggest visualization techniques, and describe possible users. This, we hoped, would bring out the topics that the students personally cared about. The received project proposition brought to 
light many individual interests (e.g. visualization of 20.000 auctions from the on-line game World-of-Warcraft; visualization of web search results or of traffic analyses) but also of some "hot spots", e.g. visualization of medical, weather or ecological data, that were suggested by several students, but for individually different data sets. In a group effort between all tutors, 7 projects that seemed representative (and interesting) of the 48 data sets were selected: visualizing orthopaedic data on human striding styles utilizing a game engine; visualizing indicators of the very large OECD education data base; visualizing data of the European pollutant emission register; visualizing data of over 70 runs of one student in preparation for a marathon; network performance visualization; flow visualization of a hurricane; and medical volume visualization. Basic knowledge on visualization (by all students) and good graphics programming capabilities (by CS students) were available, but knowledge of new algorithms and/or new Application Programming Interfaces would need to be acquired and design decisions to be made to succeed in the projects.

Supporting the team building process. One major obstacle in interdisciplinary courses is that of building project teams over the first weeks of a course, while students of different disciplines are still unfamiliar with each other. So additionally to providing a common language, the goal was to also facilitate social ties to help in the team building process. While the use of social networks to get to know each other seems a good idea, the practical side of it makes it useless for a one semester course: Once each of the 48 students have become "friends" on a social network, they will slowly get to know each other. This process being too slow, we solved the problem by an early lab assignment, requesting to fill out a "private profile". The form contained information such as "my abilities for the project group", "degree program of student", "former high school", "memberships in clubs or associations", or "favourite films/books". Students were also asked for 1-2 personal pictures (this was not mandatory) and their first name. Every one of 48 students submitted this "private profile". The resulting document was made available on the web (password secured).

When choosing teams in week 4 , it was a requirement that students built teams by selecting team members from all three faculties. This ensured a distribution of similar core curriculum knowledge in each team. Students who had submitted the selected 7 projects started the team building process. Support for the selection process was also provided through the "private profiles" collected from all students.

To help students in starting up the communication process in their team, the assignment for the first group meeting included a brainstorming session on the group project. This brainstorming session was a guided role play that made sure that each of the students had a communicative role in the discussion process. This assignment intended to dampen unrealistic expectations of team members, let everyone voice their understanding of the joint project and "break the ice" in their communication. After the first meeting, each team had to meet at least once a week and keep meeting notes using a strict protocol. Meeting notes were 
also sent to tutors and lecturer. Team members present, action items for the week to come, and the date of the next meetings were obligatory items in the notes. Instructor or tutors would show up at the meetings without notice - both to help on the content of the project and with interpersonal problems, should any arise.

Qualitative and quantitative assessment of course. Admittedly, not every one of the 48 students found the topic with their personal strongest passion because, in order to build teams with different disciplines involved, we reduced the amount of projects from 48 to 7 . In all cases but one the team members became personal friends, sometimes even to the point that they would alter personal characteristics as in the case of the "Jogging Group": One runner had suggested providing data tracking over 70 of his runs via cell phone and tracker software, including running length, speed, altitude, temperature, etc. All members of the project group became runners (and very good friends) by the time the project ended. Only in one project (out of seven) the group worked incoherently, splitting into two groups, separating not disciplines but cultures.

A voluntary assessment of students, handed out in the sixth of fifteen weeks, reveals more about the course. Of 48 students, 30 students returned the survey: 18 computer science students; 9 business information systems students; and 3 non-technical students (two media science students and one literature student).

The survey revealed that only $33 \%$ of the students had previously participated in interdisciplinary courses at their university, $67 \%$ had not. The percentage of computer science students with experience in interdisciplinarity was lower than the average experience in this group. The desire of all students to later work in interdisciplinary teams was up at $90 \%$.

Students were also asked what they would like to know about each other before teaming up in a project group: they showed a strong preference (53\%) for "the abilities this person brings to the project" rather than "private information" $(10 \%)$ or "project interest" (4\%).

The number of actual face-to-face meetings for each team was one per week during the first weeks (the obligatory group meeting they had to report about) and 2, 3, or more meetings per week between week 9 and 15. Students used cell phones, Email, ICQ, SVN (a version control system), Wiki, and Skype to communicate between meetings.

The "private profiles" were used by $67 \%$ of the students to look up private information of course mates. Business information system and non-technical students used it to a higher percentage than computer science students.

After the project presentations (last week of course), each student was asked to fill out an additional survey (resulting in 46 responses). In one of those questions the percentage of contribution to the project of each individual team member was requested. This was the last chance for students to emphasize their own contribution to the project and thus boost their grade, or to point out failures of other team members in order to find a scapegoat for goals that had not worked out in the project. The closer knit the group had become, the closer 
these numbers matched. Some groups equally divided the effort by the number of team members, among those the "jogging group". Only one group had widely mismatching numbers - the only group who had turned their project in late and experienced problems throughout the project because of a cultural split as already pointed out above.

In this same - final - survey the question on their desire for interdisciplinary work was repeated. Of the 46 responding students 41 confirmed their desire to later work with interdisciplinary teams - leaving the desire in the same percentage level as before.

Examples of projects for this course and previous interdisciplinary visualization courses can be found in [23].

Did we succeed in preparing students for transdisciplinary collaboration and lifelong learning? The survey shows that students are interested in collaboration with other disciplines, but hardly get a chance to do so in the course of their CS studies. Several indicators (their agreement over individual achievement of team members, interest in personal profiles of other students, stating the desire to work on interdisciplinary teams while and after the interdisciplinary experience, and personal observation) attest to a good collaboration and interest in each other. The strategies employed (personal profiles, early team selection, common language, enforced - but supported - weekly meetings of all team members) gave students much opportunity for face-to-face meetings. Indication for miscommunication was only present in one group out of seven.

Passion for the projects was strongest visible with the "jogging group", but also with a group using a game engine to visually present their data, as well as the groups visualizing education indicators, hurricane data and medical data. In each of these groups people with personal interests on relevant visualization goals were present and could transport their enthusiasm to others on the team. Each team had to acquire new knowledge to succeed in their project. The quality and quantity of all but one of the resulting projects were very pleasing from the subjective standpoint of the educator.

\section{Implications and Future Opportunities}

In their later work lives, university graduates will need competencies in transdisciplinary collaboration and self-directed learning to cope with the complexity of real-world problems. However, many educational programs in computer science are still dominated by curriculum-driven learning (where educators set the goals and determine the content) and curricula excluding work with other disciplines (supporting tribal behaviour) rather than providing students with the opportunity to become reflective professionals allowing them to acquire the capacity for lifelong learning and respect and ability to work with the perspectives of many, formerly separate disciplines. Opening the curriculum for course work coaching students in educational experiences where they are taught how to collaborate with other disciplines, improvise, innovate, and learn when the answer is not 
known, is a challenge for the $21^{\text {st }}$ century. In this paper we presented breadthfirst and long tail as strategies to use in graduate courses to make our students more creative, imaginative, innovative, and curious beyond their own discipline by teaming up with students of other disciplines to work on a project they feel committed to out of personal interest. The authors are convinced that the competency of transdisciplinary collaboration and self-directed learning, awakened in our students, will support a new climate of problem solving in this century.

Acknowledgments. The themes of this paper reflect some of the many interest and achievements of Hermann Maurer: (1) he has been one of the pioneers to transcend the narrow boundaries of specific disciplines (to name one prominent example: he has been the leading person behind the "The Journal of Universal Computer Science (J.UCS)", a high-quality open access electronic publication dealing with all aspects of computer science); and (2) he has been a prime example of a lifelong learner himself by always being at the forefront of exploring new research topics.

Gitta Domik thanks Hermann Maurer for his inspiring lectures during her studies and being a lifelong mentor thereafter. Gerhard Fischer thanks Hermann Maurer for numerous interesting discussions during the last decade in which he learnt many new ideas.

Both authors thank the members of the Center for LifeLong Learning \& Design (L3D) at the University of Colorado at Boulder for providing background information and inspiring debates about the content of this paper. Gerhard Fischers ideas and understanding about transdisciplinary collaboration and education have greatly benefited from collaboration with Sharon Derry (University of Wisconsin) and David Redmiles (University of California at Irvine). Gitta Domik's work was inspired by a research semester at L3D in 2007/2008.

\section{References}

1. Mumford, E. (2000) "A Socio-Technical Approach to Systems Design," Requirements Engineering, 5(2), pp. 59-77.

2. Janis, I. (1972) Victims of Groupthink, Houghton Mifflin, Boston.

3. Computing Curricula 2001. http://www.acm.org/education/curric_vols/ cc2001.pdf

4. Computing Curricula 1991. CACM, June 1991, Vol. 34, No. 6, pp. 69-84

5. Klein, J. T.: A Platform for a Shared Discourse of Interdisciplinary Education. Journal of Social Science Education, Volume 5, Number 2, September 2006, pp 10-18, ISSN 1618-5293, www.jsse.org (2006)

6. Rosenfield, P. L.: The potential of transdisciplinary research for sustaining and extending likages between the health and social sciences. Social Sciences and Medicine, 35: 134357 (1992)

7. Nicolescu, B.: The transdisciplinary evolution of learning. http://www . unesco.org/ education/educprog/lwf/dl/nicolescu_f.pdf (1999).

8. Derry, S. and Fischer, G.: Toward a Model and Theory for Transdisciplinary Graduate Education. Paper presented at 2005 AERA Annual Meeting, Symposium, 
"Sociotechnical Design for Lifelong Learning: A Crucial Role for Graduate Education", Montreal, April 2005 http://13d.cs.colorado.edu/ gerhard/papers/ aera-montreal.pdf (2005)

9. Stokols, D.: Towards a Science of Transdisciplinary Action Research. American Journal of Community Psychology, 38: 63-77 (2006)

10. Clark, H. H., Brennan, S. E. (1991) "Grounding in Communication." In L. B. Resnick, J. M. Levine, S. D. Teasley (Eds.), Perspectives on Socially Shared Cognition, American Psychological Association, pp. 127-149.

11. Fischer, G. (2000) "Lifelong Learning - More Than Training," Journal of Interactive Learning Research, Special Issue on Intelligent Systems/Tools In Training and LifeLong Learning (eds.: Riichiro Mizoguchi and Piet A.M. Kommers), 11(3/4), pp. 265-294.

12. Rushmeier, H.: IEEE Workshop on Visualization Education for Non-Technical Majors: Post Workshop Materials. http://graphics.cs.yale.edu/holly/vis2006/ vis-non-tech.html (2006)

13. Fischer, G. (2005) "Distances and Diversity: Sources for Social Creativity." In Proceedings of Creativity \& Cognition, ACM, London, April, pp. 128-136.

14. Domik, G. and Goetz, F.: A Breadth-First Approach for Teaching Computer Graphics. Education Papers, pp. 1-5. Proceedings of Eurographics 2006, Vienna, Austria, September 4-8 (2006)

15. Mackinlay, J.: Automating the Design of Graphical Presentations of Relational Information. ACM Trans. on Graphics, Vol. 5, No. 2, April 1986, pp 110-141 (1986)

16. Fischer, G. (2002) Beyond 'Couch Potatoes': From Consumers to Designers and Active Contributors, in Firstmonday (Peer-Reviewed Journal on the Internet), available at http://firstmonday.org/issues/issue7_12/fischer/.

17. Anderson, C.: The Long Tail: Why the Future of Business is Selling Less of More. Publisher Hyperion 2006, ISBN 1401302378 (2006)

18. Brown, J. S., Adler, R. P.: Minds on Fire: Open Education, the Long Tail, and Learning 2.0. Available at http://www.educause.edu/ir/library/pdf/ERM0811. pdf (2008)

19. Fischer, G.: Cultures of Participation and Social Computing: Rethinking and Reinventing Learning and Education. In Proceedings of the International Conference on Advanced Learning Technologies (Icalt), IEEE Press, Riga, Latvia, pp. 1-5 (2009)

20. National-Research-Council: Beyond Productivity: Information Technology, Innovation, and Creativity. National Academy Press, Washington, DC. (2003)

21. Collins, A., Fischer, G., Barron, B., Liu, C., and Spada, H.: Long-Tail Learning: A Unique Opportunity for CSCL? In Proceedings (Vol 2) of CSCL 2009: 8th International Conference on Computer Supported Collaborative Learning, University of the Aegean, Rhodes, Greece, pp. 22-24 (2009)

22. Domik, G.: Do We Need Formal Education in Visualization? Visualization Viewpoint. IEEE Computer Graphics and Applications, Vol. 20, No. 4 (2000)

23. Domik, G.: Interdisciplinary Collaboration in a Visualization Course, Informatics Education Europe IV, November 5-9, 2009, Freiburg, Germany. 